\title{
Accelerated Phase of Myeloproliferative Neoplasms
}

\author{
Omar A. Shahin Helen T. Chifotides Prithviraj Bose Lucia Masarova \\ Srdan Verstovsek \\ Department of Leukemia, The University of Texas MD Anderson Cancer Center, Houston, TX, USA
}

\section{Keywords}

Accelerated phase myeloproliferative neoplasms · Blast phase myeloproliferative neoplasms - Myelofibrosis . Myeloproliferative neoplasms · Post-myeloproliferative neoplasm acute myeloid leukemia

\begin{abstract}
Background: Myeloproliferative neoplasms (MPNs) can transform into blast phase MPN (leukemic transformation; MPN-BP), typically via accelerated phase MPN (MPN-AP), in $\sim 20-25 \%$ of the cases. MPN-AP and MPN-BP are characterized by $10-19 \%$ and $\geq 20 \%$ blasts, respectively. MPN-AP/BP portend a dismal prognosis with no established conventional treatment. Allogeneic hematopoietic stem cell transplantation (allo-HSCT) is the sole modality associated with longterm survival. Summary: MPN-AP/BP has a markedly different mutational profile from de novo acute myeloid leukemia (AML). In MPN-AP/BP, TP53 and IDH1/2 are more frequent, whereas FLT3 and DNMT3A are rare. Higher incidence of leukemic transformation has been associated with the most aggressive MPN subtype, myelofibrosis (MF); other risk factors for leukemic transformation include rising blast counts above 3-5\%, advanced age, severe anemia, thrombocytope-
\end{abstract} CALR-unmutated status, lack of driver mutations (negative for JAK2, CALR, or MPL genes), adverse cytogenetics, and acquisition of $\geq 2$ high-molecular risk mutations (ASXL1,EZH2, $I D H 1 / 2$, SRSF2, and $U 2 A F 1^{Q 157}$ ). The aforementioned factors have been incorporated in several novel prognostic scoring systems for MF. Currently, elderly/unfit patients with MPN$\mathrm{AP} / \mathrm{BP}$ are treated with hypomethylating agents with/without ruxolitinib; these regimens appear to confer comparable benefit to intensive chemotherapy but with lower toxicity. Retrospective studies in patients who acquired actionable mutations during MPN-AP/BP showed positive outcomes with targeted AML treatments, such as IDH1/2 inhibitors, and require further evaluation in clinical trials. Key Messages: Therapy for MPN-AP patients represents an unmet medical need. MF patients, in particular, should be appropriately stratified regarding their prognosis and the risk for transformation. Higher-risk patients should be monitored regularly and treated prior to progression to MPN-BP. MPN-AP patients may be treated with hypomethylating agents alone or

Omar A. Shahin, MD, and Helen T. Chifotides, PhD, contributed equally to this work and share first authorship.

Correspondence to:

Srdan Verstovsek, sverstov@ mdanderson.org 
in combination with ruxolitinib; also, patients can be provided with the option to enroll in rationally designed clinical trials exploring combination regimens, including novel targeted drugs, with an ultimate goal to transition to transplant.

(c) 2021 S. Karger AG, Basel

\section{Introduction}

Aberrant proliferation of hematopoietic stem cells and pro-inflammatory cytokine release, megakaryocytic atypia and bone marrow fibrosis are the main features of myelofibrosis (MF), the most aggressive among Philadelphia negative $\left(\mathrm{Ph}^{-}\right)$myeloproliferative neoplasms (MPNs). Clinically, MF manifests with anemia and thrombocytopenia, hepatosplenomegaly, extramedullary hematopoiesis, and constitutional symptoms that compromise quality of life $[1,2]$. MF can present as primary (PMF) or as a complication of preceding polycythemia vera (PV) or essential thrombocythemia (ET) (termed post-PV MF and post-ET MF, respectively) [3]. Dysregulated JAK/STAT signaling is a hallmark of MPN, primarily arising from JAK2 mutations in exon 14 (primarily the valine to phenylalanine point mutation at codon 617 in the pseudokinase domain of JAK2) or other activating JAK2 mutations in exon 12, the myeloproliferative leukemia $(M P L)$ gene, and indels in exon 9 of the calreticulin $(C A L R)$ gene $[4,5]$.

$\mathrm{MF}$ has the worst prognosis among MPNs, whereas $\mathrm{PV}$ and ET are relatively indolent subtypes [6]. The most concerning complication of PMF and post-PV MF/postET MF is leukemic transformation, which occurs in 20$25 \%$ of the cases [7]. At 10 years, the estimated incidence of leukemic transformation is the highest for MF (10$20 \%)$ followed by PV (2.3-14.4\%), and it is lowest in ET $(0.7-3 \%)[7,8]$. Accordingly, in a retrospective analysis that assessed the outcomes of 795 MPN patients, the annual incidence of leukemic transformation was highest in PMF patients when compared to PV $(p=0.002)$ or ET $(p=0.02)[9]$.

Progression from MPN in the chronic phase (MPN-CP) to MPN in the blast phase (MPN-BP) usually evolves through MPN in the accelerated phase (MPN-AP) [10]. MPN-CP, MPN-AP, and MPN-BP are defined on the basis of blast percentage in the bone marrow or peripheral blood, that is, $0-9 \%, \geq 10-19 \%$, and $20 \%$ or more, respectively (Table 1) [11-13]. In MPNs, leukemic transformation is associated with dismal prognosis, and great efforts have been made to identify the risk factors and molecular events associated with disease evolution and progression to MPN-BP.
Table 1. MPN-CP, MPN-AP, and MPN-BP; and blast counts in the bone marrow or peripheral blood

\begin{tabular}{llcc}
\hline MPN phase & MPN type & $\begin{array}{l}\text { BM blast } \\
\text { count, \% }\end{array}$ & $\begin{array}{l}\text { PB blast } \\
\text { count, \% }\end{array}$ \\
\hline Chronic & PMF, PV, ET & $>1-9$ & $>1-9$ \\
Accelerated & PMF, PV, ET & $\geq 10-19$ & $10-19$ \\
Blast & PMF, PV, ET & $\geq 20$ & $\geq 20$ \\
\hline
\end{tabular}

MPN-CP, myeloproliferative neoplasm in chronic phase; MPN-AP, myeloproliferative neoplasm in accelerated phase; MPN-BP, myeloproliferative neoplasm in blast phase; $\mathrm{BM}$, bone marrow; $\mathrm{PB}$, peripheral blood; $\mathrm{PMF}$, primary myelofibrosis; PV, polycythemia vera; ET, essential thrombocythemia.

In general, advanced age, severe anemia, leukocytosis, circulating blasts $>2 \%$, thrombocytopenia, advanced bone marrow fibrosis, cytogenetic abnormalities and acquisition of $\geq 2$ high-risk mutations were defined as clear risk factors for leukemic transformation in many studies [2, 7, 14-16]. Given that MPN-AP precedes MPN-BP in most patients, the aforementioned factors can be assessed as risk predictors of transformation from CP to MPN-AP [17]. Clinical data and treatments for MPN-AP are limited because the majority of investigations have been conducted in patients with MPN-CP and not MPN-AP/BP [18]. Clinical practice, however, has clearly demonstrated that patients with MPN-AP/BP have a dismal outcome (worse than de novo acute myeloid leukemia, AML), which is attributed to the inherent nature of the disease and the dearth of standard management or diseasemodifying treatments $[19,20]$. Currently, the sole modality that confers prolonged survival and potentially cures the disease is consolidative allogeneic hematopoietic stem cell transplantation (allo-HSCT), but a limited number of patients qualify for this option [19, 21-29]. In this review, we aim to highlight the key concepts and findings that have emerged for MPN-AP, primarily on the basis of retrospective studies, mounting evidence from clinical practice; and a limited number of clinical trials that have assessed therapeutic schemes in this population, facing adverse prognosis and a dearth of treatment modalities heretofore.

\section{Retrospective Studies, Risk Factors, and Prognostication in MPN-AP}

Our team retrospectively analyzed the clinical characteristics of 370 patients with PMF (79\% of the patients) and secondary MF (post-PV MF and post-ET MF) who 
had a median overall survival (OS) of 12 months or less to determine the characteristics of MPN-AP and identify a set of progression-associated criteria [10]. Multivariable analysis of the putative high-risk AP characteristics associated with median OS $\leq 12$ months was performed; baseline bone marrow or circulating blasts $\geq 10 \%$, aberrations of chromosome 17 , and platelet counts below $50 \times 10^{9} / \mathrm{L}$ were associated with median OS of 10, 5, and 12 months, respectively. These high-risk features were also validated during the disease course; for example, patients who were in the chronic phase and subsequently developed one of the aforementioned characteristics had similarly short survivals (median OS 12, 6, and 15 months, respectively). Moreover, the rate of leukemic transformation of patients who persistently were in MPN-CP was very low ( $1 \%$ at 3 years and $3 \%$ at 10 years, $p<0.001)$ as compared to patients in MPN-AP. These findings clearly demonstrate that transformation to MPN-BP from an antecedent MPN transitions through MPN-AP [10].

Our group recently assessed the role of increased blasts in the outcome of patients with MF [30, 31]. In a cohort of 1,316 MF patients with available counts of peripheral and bone marrow blasts, we showed that patients with $4 \%$ peripheral blasts and $\geq 5 \%$ bone marrow blasts had comparable OSs and clinical characteristics and also resembled patients in AP (blasts $\geq 10-19 \%$ ). The respective OSs of patients with $0,1-3,4 \%$ peripheral blasts (and $<5 \%$ bone marrow blasts), 5-9\% peripheral and/or bone marrow blasts, and $\geq 10-19 \%$ peripheral and/or bone marrow blasts were $64,48,22,24$, and 13 months, respectively. Overall, 146 patients progressed to AML, with the highest rate among those with $\geq 10 \%$ blasts, as expected; however, patients with $5-9 \%$ blasts had an approximate twofold rate of leukemic transformation as compared to patients with lower blasts (AML incidence per 100 person-years was 7.7 and 24.7 cases for $5-9 \%$ and $\geq 10 \%$ blasts, respectively, vs. 3.5 cases only for blasts $\leq 4 \%$ ) $[30,31]$. The estimated leukemia-free survival (LFS) rate at 3 years was $\sim 60 \%$ for patients with $<5 \%$ blasts, and $\sim 30 \%$ for those with $\geq 5 \%$ blasts [30]. Patients who had blasts $<10 \%$ and were treated with ruxolitinib had superior overall survival compared to patients who did not receive ruxolitinib [31].

Geyer and colleagues [32] conducted a retrospective study in which 92 patients with initial diagnosis of PMF, $\mathrm{PV} /$ post-PV MF, and ET/post-ET MF (median follow-up time was 11 years) and increased blasts were stratified in 3 categories according to blast counts: IB- 1 ( $2-4 \%$ peripheral blood blasts and $<5 \%$ bone marrow blasts), IB-2 (5$9 \%$ blasts in the bone marrow and/or peripheral blood), and AP $(\geq 10-19 \%$ blasts in bone marrow or peripheral blood); also, the investigators identified a control group comprising MPN patients who did not have increased blasts, leukocytosis, or monocytosis. The analysis demonstrated that patients in the IB-2 group $(p=0.00014)$ had a significantly inferior OS than both the IB-1 group and control patients; in contrast, the OS rates of group IB-1 and the controls were similar. As expected, patients in the combined IB-1/IB-2 groups $(p=0.0038)$ and the controls $(p<0.0001)$ had significantly longer OSs than patients in AP [32]. The 2 aforementioned studies by Masarova et al. [30] and Geyer et al. [32] indicate that lowering the blast percentage threshold defining MPN-AP from 10\% to 5\% is justified $[25,33]$. Notwithstanding designation of bone marrow or peripheral blood blasts $\geq 20 \%$ as indication of MPN-BP by the International Working Group-Myeloproliferative Neoplasms Research and Treatment (IWGMRT) in 2013 [3], blast counts in the range 10-19\% have been associated with MPN-AP and clearly inferior outcomes $[10,30]$; in clinical practice, the former blast range is currently applied as a criterion of advanced MPN disease and thus could be included in the next revision of the criteria. In a retrospective study of 311 patients with PMF, aiming to assess the risk factors leading to leukemic transformation, peripheral blood blasts $\geq 3 \%(p<0.0001)$ and platelet counts below $100 \times 10^{9} / \mathrm{L}(p=0.004)$ were determined to be strong and independent risk factors in both univariate and multivariate analyses [34]. When the previous factors were taken into consideration, the frequency of leukemic transformation increased from $5.8 \%$ in the subgroup with neither one of the 2 risk factors to $18.2 \%$ in the subgroup that had both [34]. In a recent large study including 1,306 patients with PMF, Vallapureddy and colleagues [35] demonstrated that peripheral blasts $\geq 3 \%$ were associated with increased risk of leukemic transformation (HR 3.3) in the first 5 years of diagnosis. Other retrospective studies led to the conclusion that red blood cell (RBC) transfusion dependence and high white blood cell (WBC) counts were correlated with elevated risk of transformation $[36,37]$.

Several prognostic models were developed to assess the outcome of PMF patients [38]. The initial International Prognostic Scoring System (IPSS) [39] relies on clinical parameters at diagnosis and was modified to the Dynamic IPSS (DIPSS) to assess prognosis based on risk factors at diagnosis and during the natural history of the disease [40]. In DIPSS, age over 65 years (1 point), hemoglobin $<10$ g/dL ( 2 points), WBC count $>25 \times 10^{9} / \mathrm{L}(1$ point), peripheral blood blasts $\geq 1 \%$ ( 1 point), and constitutional symptoms (1 point) predicted poor survivals. In 
Table 2. Two-tiered versus the revised 3-tiered cytogenetic risk models and risk categories in PMF

\begin{tabular}{|c|c|c|c|}
\hline $\begin{array}{l}\text { Two-tiered cytogenetic risk categories } \\
\text { according to Caramazza et al. [46] }\end{array}$ & $\begin{array}{l}\text { Cytogenetic } \\
\text { risk category }\end{array}$ & $\begin{array}{l}\text { Revised 3-tiered cytogenetic risk categories } \\
\text { according to Tefferi et al. [48] }\end{array}$ & $\begin{array}{l}\text { Cytogenetic } \\
\text { risk category }\end{array}$ \\
\hline $\begin{array}{l}\text { Complex karyotype } \\
\text { Sole or } 2 \text { abnormalities that include } \\
\quad+8 \\
\quad-7 / 7 \mathrm{q}- \\
\mathrm{i}(17 \mathrm{q}) \\
-5 / 5 \mathrm{q}- \\
12 \mathrm{p}- \\
\text { inv }(3) \\
11 \mathrm{q} 23 \text { rearrangement }\end{array}$ & Unfavorable & $\begin{array}{l}\text { Complex karyotype without a VHR abnormality } \\
\text { Sole abnormalities that include } \\
\quad+8 \\
\quad-7 \mathrm{q}- \\
\text { Sole translocations not involving chromosome } 1 \\
\text { Two abnormalities not including a VHR abnormality } \\
\text { Single/multiple } 5 \mathrm{q}-\text { abnormalities } \\
\text { Monosomal karyotype without a VHR abnormality } \\
\text { Sole abnormalities not otherwise classified }\end{array}$ & Unfavorable \\
\hline & & $\begin{array}{l}\text { Single/multiple abnormalities of } \\
\quad \operatorname{inv}(3) / 3 \mathrm{q} 21 \\
\quad-7 \\
11 \mathrm{q}-/ 11 \mathrm{q} 23 \\
12 \mathrm{p}-/ 12 \mathrm{p} 11.2 \\
\mathrm{i}(17 \mathrm{q}) \\
\text { Autosomal trisomies, not including }+8 \text { or }+9 \text { (e.g., } \\
+19,+21)\end{array}$ & VHR \\
\hline $\begin{array}{l}\text { Normal karyotype } \\
\text { Sole abnormalities of } \\
\quad+9 \\
\quad 13 \mathrm{q}^{-} \\
\quad 20 \mathrm{q}- \\
\text { Chromosome } 1 \text { translocation/duplication } \\
\text { Two abnormalities excluding unfavorable } \\
\text { ones }\end{array}$ & Favorable & $\begin{array}{l}\text { Normal karyotype } \\
\text { Sole abnormalities of } \\
\quad+9 \\
\quad 13 \mathrm{q}- \\
\quad 20 \mathrm{q}- \\
\text { Chromosome } 1 \text { translocation/duplication } \\
\text { Sex chromosome abnormality, including }-\mathrm{Y}\end{array}$ & Favorable \\
\hline
\end{tabular}

PMF, primary myelofibrosis; VHR, very high-risk.

DIPSS, patients were stratified into 4 categories: low (0 points), intermediate-1 (1-2 points), intermediate-2 (3-4 points), and high risk (5-6 points) [40]. The estimated hazard risk for progression to $\mathrm{BP}$ was 2 when the risk category progressed from low to intermediate-1, 3.8 from intermediate- 1 to intermediate- 2 , and 3.2 from intermediate-2 to high. The risk to develop MPN-BP in the intermediate-2 and high categories was 7.8- and 24.9-fold higher than in the low-risk category, respectively [41]. On the basis of the evidence acquired from follow-up data of PMF patients, karyotype, transfusion dependence, and thrombocytopenia (platelet counts $<100 \times 10^{9} / \mathrm{L}$ ) were integrated in the DIPSS, thereby developing DIPSS-plus [42], which turned out to be superior in assessing the LFS than both IPSS and DIPSS. Thrombocytopenia and anemia were also included in the more integrated MutationEnhanced International Prognostic Scoring System 70 (MIPSS70) for transplant-eligible patients with PMF aged $\leq 70$ years [43] and in the Myelofibrosis SECondary to PV and ET-Prognostic Model (MYSEC-PM) for post-PV MF/post-ET MF [44].

Cytogenetic abnormalities constitute an important risk factor in progression of MF-CP to MF-AP/BP [7]; however, cytogenetics were not included as a factor in the IPSS [39] and DIPSS [40]. Hussein and colleagues [45] showed the prognostic relevance of specific cytogenetic abnormalities (e.g., +8 or complex karyotype) and the favorable prognostic impact of sole $20 \mathrm{q}-, 13 \mathrm{q}-$, or +9 [4648]. In a more recent study on 1,002 patients with MF, the same investigators showed that $45 \%$ of the patients had abnormal karyotype; $6 \%$ of the latter subgroup had complex karyotype ( 3 or more abnormalities), and of those, about one-third had a monosomal karyotype [48]. In a cohort of patients with PMF, the 2-year leukemic transformation rate associated with monosomal karyotype was $29.4 \%$, and the median survival was 6 months versus $8.3 \%$ and 24 months, respectively, for complex karyotype without monosomies, demonstrating the dismal progno- 
sis associated with certain monosomies [49]. The unfavorable karyotype category of the 2-tiered cytogenetic model for PMF includes complex karyotype and 1 or 2 abnormalities, for example, $+8,-5 / 5 q-,-7 / 7 q-, 12 p-$, $\mathrm{i}(17 \mathrm{q})$, inv(3), and $11 \mathrm{q} 23$ rearrangement $[42,46]$ (Table 2). Notably, Tefferi and colleagues [48] recently proposed a more refined 3-tiered cytogenetic stratification, comprising very high-risk (VHR), unfavorable, and favorable karyotype categories (Table 2). The VHR karyotype showed inferiority in LFS regardless of other risk factors, such as high-risk mutations, thrombocytopenia, and DIPSS [48]. The 3-tiered cytogenetic model has been integrated in the 5-tiered Mutation and Karyotype-Enhanced MIPSS70-plus version 2.0 [50] and the 4-tiered Genetically Inspired Prognostic Scoring System (GIPSS) [51] for PMF. On the other hand, the 2-tiered cytogenetic model (comprising favorable and unfavorable categories) has been incorporated in DIPSS-plus [42] and MIPSS70-plus [43]. The recent refined 3-tiered cytogenetic model was developed based on a cohort of 1,002 PMF patients at Mayo Clinic [48] and was further evaluated in the studies that led to the development of MIPSS70plus version 2.0 [50] and GIPSS [51]. Validation of the 3 -tiered model is necessary as preliminary results from our group did not confirm the same discrimination power of the 3-tiered model [52].

A recent study, which Marcellino and colleagues [53] conducted on the impact of chromosomal abnormalities in advanced MPN, showed that $43 \%$ of the patients with MPN-AP/BP gained $+1 \mathrm{q}$ versus 9 and $2 \%$ in the MF and $\mathrm{PV} / \mathrm{ET}$ cohorts, respectively; and $+1 \mathrm{q}$ was recurrently detected in MPN-AP/BP $[53,54]$. Notably, $+1 \mathrm{q}$ was detected in the majority of MPN patients (84\%) who harbored $J A K 2^{\mathrm{V} 617 \mathrm{~F}}$ [53]. Furthermore, all the patients with MPNAP/BP (33\%), PMF (50\%), and secondary MF (17\%) exhibited loss of $17 \mathrm{p} 13$ (leading to TP53 deletion) versus none with PV/ET, findings clearly indicating the association of $17 p$ deletions with advanced MPN [53].

A retrospective analysis of 649 patients with MF demonstrated that baseline bone marrow or peripheral blood blasts $\geq 5 \%$ ( $p=0.02$ and 0.01 , respectively) and unfavorable karyotype $(-5,-7$, del17p, and/or complex karyotype, $p=0.04$ ) were independent risk factors for leukemic transformation [55]. The subgroup that had one or both risk factors ( 80 patients, $12 \%$ of the cohort) had a median OS of 10 months and a considerably higher risk of leukemic transformation versus patients without either one of the 2 adverse factors; the 1-year LFS was $82 \%$ compared to $98 \%$, respectively $(p=0.001)$, at 1 year. During a 12 -month follow-up, $13 \%(n=10)$ of 80 patients who had either one of the 2 risk factors progressed to AML compared to $2 \%(n=10)$ of 568 patients without the previous characteristics [55]. Acquisition of an abnormal karyotype has also been associated with higher incidence of disease progression in PV $[16,56]$. In studies conducted at the MD Anderson Cancer Center, an abnormal karyotype was detected in about $14-20 \%$ of the patients with PV; in contrast, the frequency increased to $90 \%$ in the AP/ BP patients, of whom $83 \%$ had complex karyotype [56]. In this study, another factor that was associated with higher risk of leukemia transformation, and later others confirmed it, was the presence of moderate to severe bone marrow fibrosis and dysplasia $[8,16]$. Expectedly, higher grades of bone marrow fibrosis correlated with advanced disease and adverse prognosis in PMF $[57,58]$ and have been incorporated in the MIPSS70-plus version 2.0 model [43].

Dobrowolski and colleagues [59] demonstrated that correlation of leukemic transformation risk and persistent basophilia in PMF in the fibrotic stage was statistically significant. Other groups showed that monocytosis was a strong adverse indicator of progression to the accelerated phase and inferior survival in patients with PMF [60-62]. A recent study conducted in 454 patients with PMF revealed that monocytosis was associated with leukemic transformation: an absolute monocyte count $\geq 1 \times$ $10^{9} / \mathrm{L}$ and $>3 \times 10^{9} / \mathrm{L}$ increased the hazard risk by 2 - and 4 -fold, respectively [62]. Furthermore, an association was found between monocytosis and older age, increased circulating blasts, higher DIPSS, and DIPSS-plus scores, and the presence of ASXL1 [62].

Radioactive phosphorus $\left({ }^{32} \mathrm{P}\right)$, pipobroman, and busulfan, used in PV treatment, have been associated with increased risk of leukemogenesis $[7,63]$. In a retrospective analysis of 83 patients with MPN followed up for nearly 8 years, $14 \%, 30 \%$, and $4 \%$ of the patients who were treated with hydroxyurea monotherapy, hydroxyurea and busulfan, or merely observed developed AML/myelodysplastic syndrome (MDS) [64]. In a national study on a large Swedish cohort of patients with MPN $(n=11,039)$, transformation to AML/MDS ( $n=$ 162) significantly increased with high doses of ${ }^{32} \mathrm{P}$ and alkylating agents (and the risk increased 2.9-fold with $\geq 2$ treatments), whereas there was no association between the use of hydroxyurea and elevated risk of AML/MDS [65]. Researchers from Mayo Clinic also analyzed the effect of specific treatments on LFS and concluded that erythropoiesis-stimulating agents and danazol were both associated with significantly shorter LFS on univariate analysis [34]; however, these find- 
ings were not confirmed in subsequent studies by other researchers. Other proposed factors contributing to disease progression to MF-AP and MF-BP include high levels of circulating pro-inflammatory mediators, such as interleukin- 8 and C-reactive protein $(>7 \mathrm{mg} / \mathrm{L})$ $[66,67]$.

\section{Molecular Signatures of MPN-AP/BP}

Approximately $90 \%$ of the patients with PMF harbor one of the 3 "driver" mutations. Janus kinase 2 (JAK2) V617F, calreticulin (CALR) exon 9 indels, and myeloproliferative leukemia virus oncogene $(M P L) \mathrm{W} 515 \mathrm{~L} / \mathrm{K}$ were detected in about $50-60 \%, 20-30 \%$, and $5-10 \%$ of the patients, respectively [68]. Nearly $10 \%$ of PMF patients have "triple negative" molecular status regarding "driver" mutations, which is a high-risk profile and has been associated with significantly worse LFS $[69,70]$. In a retrospective analysis of 1,581 patients with MPNs, including 428 with PMF, patients with "triple negative" status for the 3 driver mutations (JAK2, CALR, and MPL) had significantly worse LFS than those harboring JAK2 (HR 0.4; 95\% CI, 0.2-0.7), CALR (HR 0.1; 95\% CI, 0.05-0.35), and MPL (HR 0.3; 95\% CI, 0.1-0.9) mutants [71]. Accordingly, OS was considerably longer in patients harboring CALR versus "triple-negative" (HR 5.1; 95\% CI) and JAK2 mutants (HR 2.5; 95\% CI) [71]. An international study of 570 patients with PMF showed that type $1 C A L R$ mutations conferred the longest survival in the absence of ASXL1 (median 10.4 years); conversely, the shortest survival was detected in mutated-ASXL1 and unmutated$C A L R$ cases [72]. A favorable correlation has been identified between $C A L R$ type 1 mutations and longer survival [70]. Unmutated-CALR (type 1) status is one of the factors incorporated in MIPSS70 [43] (1 point), MIPSS70plus version 2.0 ( 2 points) [50], GIPSS (1 point) [51], and MYSEC-PM (2 points) [44].

A retrospective study assessing a gene panel including 27 MPN-related mutations in 182 patients with PMF showed that $81 \%$ ( $n=147$ patients) harbored other mutations/variants apart from JAK2/CALR/MPL [69]. The most frequent mutations were ASXL1 (36\%), SRSF2 (18\%), TET2 (18\%), and U2AF1 (16\%) [69]. SRSF2, RUNX1, CEBPA, and SH2B3 were associated with higher risk of leukemic transformation (HR was $4.9,8.7,5.4$, and 5.8, respectively) [69]. In a larger analysis of $879 \mathrm{MF}$ patients comprising 2 cohorts (European study group, $n=483$, and validation group from Mayo Clinic, $n=396$ ), the most common "non-driver" muta- tions were ASXL1 (21.7\%), TET2 (9.7\%), SRSF2 (8.5\%), DNMT3A (5.7\%), EZH2 (5.1\%), CBL (4.4\%), and IDH1/2 (2.6\%) [73]. The study led to the conclusion that ASXL1,IDH1/2, and SRSF2 were independently correlated with leukemogenesis; ASXL1,EZH2, and $S R S F 2$ were independent predictors of shortened survival; and ASXL1, SRSF2, EZH2 and IDH1/2 were identified as high-molecular risk (HMR) mutations [73]. The cumulative risk of transformation to MPN-BP was considerably higher, and LFS was significantly lower in the HMR group as compared to the low-risk group (no HMR mutations) [73]. The aforementioned HMR mutations were incorporated in MIPSS70 [43], and $U 2 A F 1^{\mathrm{Q} 157}$ mutations were added to the MIPSS70-plus version 2.0 [50] after the negative prognostic value of $U 2 A F 1^{\mathrm{Q} 157}$ mutations in PMF was demonstrated [74]. Another study illustrated the association between significantly shorter LFS and the presence of $\geq 2$ HMR mutations (HR 6.2) [71], a criterion that was incorporated in the MIPSS, MIPSS70-plus, MIPSS70-plus version 2.0 , and GIPSS models $[38,68,75]$.

Moreover, an extended exome-sequencing analysis of 69 genes in $>2,000 \mathrm{MPN}$ patients demonstrated that mutations in the RAS pathway and spliceosome and epigenetic regulators had a strong association with MF-AP [14], and patients harboring NRAS/KRAS mutations had a higher incidence of progression to AML [76]. A recent study on 1,306 patients with PMF corroborated association of ASXL1 (HR = 2.0), SRSF2 (HR 3.0), and IDH1 $(\mathrm{HR}=4.3)$ with the highest risk of transformation [35]. A few studies showed that TP53 mutations were strongly associated with progression to BP for all classic MPN subtypes $[16,54,75,77]$. Accordingly, Marcellino and colleagues [53] demonstrated that advanced forms of MPNs are accompanied by chromosomal abnormalities that lead to dysregulation of TP53. TP53 mutations co-occurred with $J A K 2^{\mathrm{V} 617 \mathrm{~F}}$ in patients who had MPN-BP and increased during leukemic transformation [78]. Lundberg and colleagues [79] demonstrated the strong association of TP53 loss with leukemogenesis as opposed to the presence of heterozygous TP53 at low allelic burden during MPN-CP. In another recent study, multivariate analysis showed that RUNX1 mutations correlated with shorter survival in a cohort of 248 patients with MPN-BP [80].

The mutational profiles of MPN-AP and MPN-BP are similar, given that $\mathrm{AP}$ precedes $\mathrm{BP}$ in the majority of the patients [10]. However, the mutational landscape of MPN-AP/BP has marked differences from that of both de novo AML and MPN-CP [17, 78]. For example, IDH1/2 and TP53 mutations have a higher frequency in 
Fig. 1. Mutational landscape (excluding "driver" mutations) in patients with MPN$\mathrm{AP} / \mathrm{BP}(N=122,14$ in AP and 108 in BP $)$. Data shown in the plot were reported by McNamara and colleagues [88]. MPN-AP, myeloproliferative neoplasm in accelerated phase; MPN-BP, myeloproliferative neoplasm in blast phase.

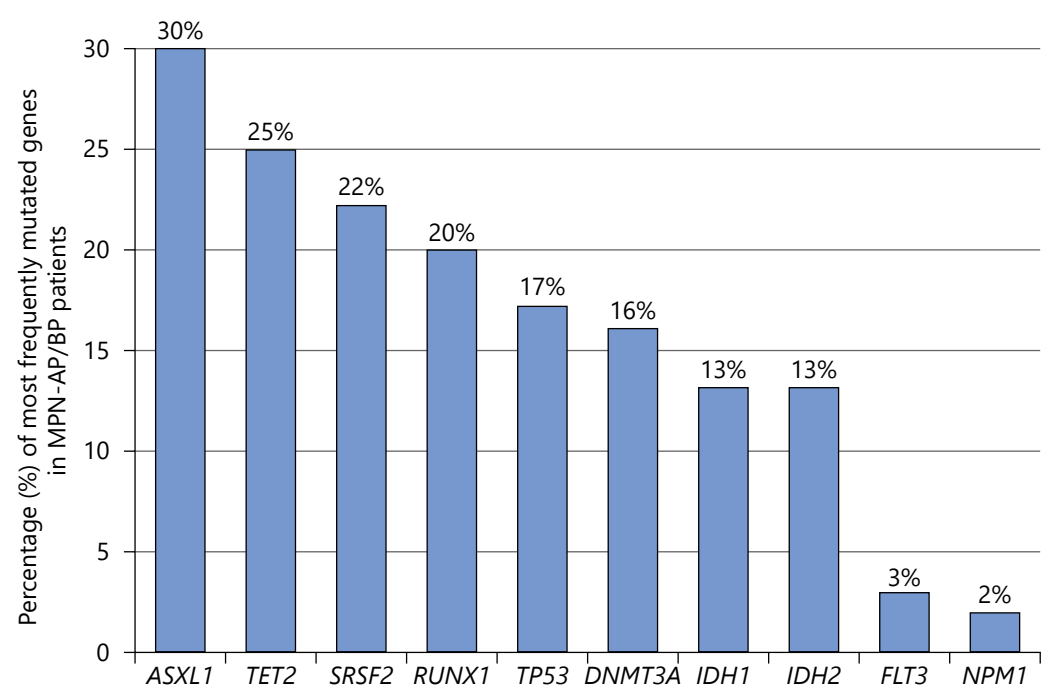

low serum albumin, and $>3$ cytogenetic abnormalities were correlated with shorter survival $[10,88]$. Patients with AP/BP that harbored ASXL1 were more likely to have 3 -fold higher WBC counts $(p=0.04)$ [88], and patients with ASXL1-mutated MPN had significantly lower hemoglobin levels than the wild-type subgroup [79]. Furthermore, acquisition of ASXL1 along with JAK2 $2^{\mathrm{V} 617 \mathrm{~F}}$ cooperated in accelerating progression to MF in PV patients [89]. In a cohort comprising 42 patients with high-risk MF and MPN-AP/BP, the most frequent co-occurring mutations were ASXL1 and JAK2 ${ }^{\mathrm{V} 617 \mathrm{~F}}[90]$.

Recently, our group showed that concomitant presence of $J A K 2^{\mathrm{V} 617 \mathrm{~F}}$ and $J A K 2$ "variants" was associated with increased risk of leukemic transformation in patients with MF [91]. Analyses of the 28-gene panels of bone marrow specimens from 2,154 patients with MPN $(n=608)$, AML/MPN $(n=59)$, and de novo AML $(n=$ 1,487 ) revealed JAK2 "variants" (non-V617F/non-exon $12 J A K 2$ variants) in 114 patients [91]. Among all tested patients, $23(20.2 \%)$ had a co-occurring JAK2 $2^{\mathrm{V} 617 \mathrm{~F}} \mathrm{mu}$ tation. The 3 most frequent variants were N1108S, $\mathrm{L} 393 \mathrm{~V}$, and $\mathrm{R} 1063 \mathrm{H}$ across the 3 subgroups. JAK2 "variants" were considerably more frequent in the MPN-BP subgroup ( 15\%) than in the MPN ( 5\%) and de novo AML (5.2\%) subgroups. Patients harboring both $J A K 2^{\mathrm{V} 617 \mathrm{~F}}$ and a JAK2 "variant" had an increased cumulative risk to progress from MPN to AML compared to those with $J A K 2^{\mathrm{V} 617 \mathrm{~F}}$ only $(p=0.003)$ [91]. 
Moreover, further mutational analysis demonstrated that TP53 was found in $~ 51 \%$ of the patients harboring a JAK2 "variant" [91].

\section{Therapeutic Modalities}

As noted in the previous sections, MPN-AP usually precedes MPN-BP [10], and both phases are inherently associated with a poor prognosis. Historically, the median OS for MPN-BP has been in the approximate range of 3-9 months [7, 19, 24, 92]. Treatment options and management for MPN-AP/BP are largely similar, and at present, there is no standard approved therapy $[25,92]$. At our institution, we usually treat MPN-AP/BP patients with hypomethylating agents (decitabine and azacitidine) in combination with ruxolitinib - ruxolitinib is typically added at the dose of $10 \mathrm{mg}$ twice daily to control splenomegaly and MPN symptoms to the degree possible, and this dose/schedule is maintained despite lowering of the blood counts as expected from hypomethylating agents which has become standard practice, as it appears to provide at least equal benefit (but lower toxicity) to intensive chemotherapy. In the cases of MPN-BP patients with $I D H 1$ and IDH2 mutations, we administer combinations with ivosidenib or enasidenib or enroll them in clinical trials. In rare instances of FLT3-mutated MPN-BP, gilteritinib is included in the regimen. Patients who can achieve complete or partial remission or return to a second chronic phase are referred for allo-HSCT. Our experience and that of other investigators have shown that early detection of targetable mutations (e.g., IDH1 and $I D H 2$ ) and timely initiation of the appropriate treatment play an important role in efficacious treatment of patients with advanced-phase MPN. In patients who are fit for transplantation and do not harbor targetable mutations, we recommend allo-HSCT after intensive chemotherapy and achievement of CR or return to MPN-CP [93].

\section{Allogeneic Hematopoietic Stem Cell Transplant}

The importance of accurate risk stratification of MF patients $[68,75,94,95]$ and timely referral of MF patients for allo-HSCT evaluation in all categories except for low risk was demonstrated in a recent study [96]. Allo-HSCT is recommended in patients with intermediate- 2 or highrisk MF according to the IPSS, DIPSS, or DIPSS-plus criteria, or intermediate- 1 disease in the presence of unfavorable karyotype according to the DIPSS-plus criteria [42], HMR mutations (e.g., "triple-negative" MPN "driver" mutations, mutated $A S X L 1$, and $I D H 1 / 2)$, transfu-

Accelerated Phase MPN sion-dependent anemia, and peripheral blasts $>2 \%$ [96]. The National Cancer Comprehensive Network (NCCN) recommends consideration of blasts in the range 10-19\% in the peripheral or bone marrow for MPN-AP diagnosis [97]. However, a few recent studies showed an association of blasts $\geq 3 \%$ with leukemic transformation [35] and $\geq 5 \%$ with leukemic transformation and inferior survival [3032]. As detailed in the section on risk factors of advancedphase MPN, Masarova and colleagues [30, 31] demonstrated the prognostic value of bone marrow and peripheral blood blasts $\geq 5 \%$ in patients with MF; the findings of the former studies clearly underscore that blasts $\geq 5 \%$ should be taken into consideration along with unfavorable karyotypes and HMR mutations in patients with MF.

The myelofibrosis transplant scoring system (MTSS) was recently developed to predict the outcome of patients with primary and secondary MF after allo-HSCT on the basis of pretransplant factors [94]. Patients who can sustain intensive chemotherapy and achieve complete or partial remission or return to a second chronic phase have the option of consolidative allo-HSCT [21, 22, 24, 28, 29]. Up to the present, standardized criteria for response assessment to treatment of MPN-AP/BP have not been well established. Several studies have shown that complete remission (CR) prior to transplant was the most critical factor affecting survival in patients with MF that had transformed to AML [21, 22, 28, 29]. For example, Alchalby and colleagues [22] showed that approximately 3 times more patients who underwent allo-HSCT in CR (69\%) were alive than patients with residual disease (22\%) after 3 years. In general, there is no consensus about the depth of the response, but typically $<5 \%$ blasts in the bone marrow and absence of peripheral blasts are considered a morphologic leukemia-free state [98]. To assess the response of patients with MPN-AP/BP to treatment, clinical investigators have been applying the European LeukemiaNet (ELN) criteria for AML published in 2017 [98], the proposed criteria for MPN-BP in 2012 [99], or both. The traditional ELN criteria assess elevation of the blast count in the bone marrow [98], which is a hallmark of the disease. However, in advanced-phase MPN, a discordance can be found in the blast counts of the bone marrow versus the peripheral blood due to extramedullary hematopoiesis. The proposed criteria for MPN-AP/BP assess both the AML and MPN components of the disease (cytogenetic/molecular responses and bone marrow fibrosis of the underlying MPN and other symptoms, such as splenomegaly) [99].

A retrospective study of 39 patients who had MPN$\mathrm{AP} / \mathrm{BP}$ and underwent allo-HSCT manifested that ap- 
Table 3. Selected clinical trials on treatments for MPN-AP/BP

\begin{tabular}{lll}
\hline Treatment regimen & Disease & Clinical trial \\
\hline Ruxolitinib + decitabine & MPN-AP/BP & NCT02076191 (phases 1 and 2) ${ }^{\ddagger}$ \\
Ruxolitinib + decitabine & MPN-BP & NCT02257138 (phase 1/2) \\
Ruxolitinib or fedratinib + decitabine & MPN-AP/BP & NCT04282187 (phase 2) \\
Ruxolitinib + enasidenib & IDH2-mutated MPN-BP & NCT04281498 (phase 2) \\
Ivosidenib + venetoclax \pm azacitidine & $I D H 1$-mutated MPN-BP & NCT03471260 (phase 1b/2) \\
Ivosidenib + azacitidine & IDH1-mutated MPN-BP & NCT03173248 (phase 3; AGILE trial) \\
Guadecitabine (SGI-110)* & MPN-AP & NCT03075826 (phase 2) \\
Ivosidenib or enasidenib + induction and consolidation therapy & IDH1-or IDH2-mutated MPN-BP & NCT02632708 (phase 1) \\
Gilteritinib & FLT3-mutated MPN-BP (rare) & NCT03836209 (phase 2) \\
KRT-232 + decitabine or low-dose cytarabine & MPN-BP & NCT04113616 (phase 1b/2) \\
\hline
\end{tabular}

MPN-AP, myeloproliferative neoplasm in accelerated phase; MPN-BP, myeloproliferative neoplasm in blast phase. ${ }^{\dagger}$ The trials were conducted exclusively $^{\dagger}$ for patients with MPN-AP and/or MPN-BP. ${ }^{*}$ Enrollment of patients with MPN-AP and/or MPN-BP was allowed in the trial. " The phase 1 and 2 studies were conducted by the MPN Research Consortium. ${ }^{\S}$ The study is planned to start in the near future. The MPN Research Consortium will conduct the study. Patients with IDH2-mutated MPN-AP/BP or MF-CP (4-9\% circulating blasts) will be enrolled. * Decitabine-P-guanosine. ${ }^{* *}$ Patients harboring TP53 mutation are excluded from this study.

proximately one-third of the patients achieved long-term survival, and the OS rate was $\sim 29 \%$ at 2 years [21]. In a recent multicenter retrospective study, the OS of $551 \mathrm{MF}$ patients who underwent allo-HSCT versus 1,377 nonHSCT patients was compared; allo-HSCT conferred long OS benefit to the former cohort, primarily in patients who had intermediate- 1 and higher DIPSS risk scores and had been treated for $>1$ year $[21,96]$. Conversely, for the first year, the OS was longer in the non-HSCT cohort that had low-risk DIPSS score and received other treatments due to mortality related to transplant (frequently caused by graft-versus-host disease) [96]. Treatment of 6 patients with MPN-BP with a combination of intensive chemotherapy $([7+3]$ type; cytarabine with idarubicin or daunorubicin) and continuous ruxolitinib resulted in 4 responders and 3 patients who were able to undergo alloHSCT [100]. Induction therapy can result in remission, but the responses are not durable unless the treatment is followed by allo-HSCT $[19,23,28,88,101]$. Many patients are precluded from allo-HSCT due to age, poor performance status, other comorbidities, and lack of a suitable donor or inability to achieve a reasonable response $[21,25,92,96]$.

\section{Hypomethylating Agents as Monotherapies and in Combination with Ruxolitinib}

Hypomethylating agents or inhibitors of DNA methyltransferases, such as azacitidine and decitabine, initially as monotherapies or in combination with ruxolitinib (JAK1/2 inhibitor), have shown synergistic preclinical [78] and clinical [7] activities with comparable response rates to intensive chemotherapy but lower toxicity in patients with MPN-AP/BP [102]. In a previous study, 54 patients with MPN who progressed to MPN-BP $(n=26)$ or myelodysplastic syndrome $(n=28)$ were treated with azacitidine; the entire cohort had a median OS of 11 months, and the CR rate for the MPN-BP subgroup was $12 \%$ [103]. A retrospective analysis of 19 MPN patients (developing MPN-BP) who were treated with azacitidine showed that 5 patients $(26.3 \%)$ achieved CR, 1 had a partial response, 4 had stable disease, and 3 displayed hematological improvement; since the time of BP evolution, the median cumulative survival was 9.9 months [104]. Andriani and colleagues [105] conducted another recent retrospective study in 39 patients who were in MPN-AP/ $\mathrm{BP}$ and were treated with azacitidine in the frontline setting at 10 hematologic centers in Italy. Hematologic responses were noted in 24 patients: 8 (20.5\%) and 7 (17.9\%) achieved complete and partial responses, respectively, whereas hematologic improvement was noted in 9 (23.1\%); 4 responders underwent allo-HSCT. The overall response rate was $61.5 \%$, and the entire cohort had a median OS of 13.5 months; the median OS for responders was about 4 months longer (17.6 months) [105]. Another phase $1 \mathrm{~b}$ study evaluated the safety and maximum tolerated dose of ruxolitinib in combination with azacitidine in a small cohort of patients comprising 7 with MPN-AP (including MDS) and 7 with MPN-BP. Of the 6 evaluable patients, 1 achieved CR, 1 reached partial remission (MPN-BP patient), and 2 had stable disease [106]. A retrospective, multicenter study (from 8 French hospitals) of 122 patients with MPN who progressed to MPN-AP/ 
BP demonstrated that the MPN-AP subgroup treated with azacitidine exhibited the longest OS in the cohort (13.6 months) [24]. In a phase 2 investigation of ruxolitinib and azacitidine at our institution (NCT01787487), among 46 enrolled MF patients, 3 had MF-AP with blasts $\geq 10 \%$ and only 1 patient achieved clinical improvement in the spleen and Total Symptom Score (per International Working Group-Myeloproliferative Neoplasms Research and Treatment criteria) with a blast reduction to $2 \%$, lasting for 28 months [107].

In 2015, we analyzed the efficacy of decitabine in 13 patients with MPN-AP at our institution [108]. Sixty-two percent $(8 / 13)$ of the patients with MPN-AP benefited from the treatment; the median duration of response was 6.5 months, with a median OS of 9.7 months [108]. In another phase 2 study at our institution, 18 patients with MPN-BP were treated with ruxolitinib monotherapy, and $3 / 18$ patients obtained CR or complete remission with incomplete hematological recovery $\left(\mathrm{CR}_{\mathrm{i}}\right)$ [109]. In a phase $1 / 2$ study (NCT02257138), we treated 12 patients who had MPN-BP with a combination of ruxolitinib and decitabine. We determined that $50 \mathrm{mg}$ ruxolitinib twice daily with the standard regimen for decitabine $\left(20 \mathrm{mg} / \mathrm{m}^{2}\right.$ for 5 days on a 4- to 6-week schedule) were tolerable and safe $[110,111]$ (Table 3). In the phase 2 study, among 18 patients with MPN-BP, treated with the recommended doses of ruxolitinib and decitabine, $61 \%$ were responders $\left(11 \% \mathrm{CR}+50 \% \mathrm{CR}_{\mathrm{i}}\right)$. The median OS was 8.4 months (range, 0.4-42.6 months) for all the patients and 9.4 months (range 3.1-42.6) for responders [111]. A multicenter phase 1 study (NCT02076191) that was designed and monitored by the Myeloproliferative Neoplasms Research Consortium also assessed the combination of ruxolitinib and decitabine in patients with MPN-AP/BP (21 patients, $n=8$ in AP and $n=13$ in BP) [112] (Table 3). The response rate and median OS were $66.7 \%$ and 16 months in the MPN-AP subgroup and $45.5 \%$ and 7.2 months in the MPN-BP subgroup [112]. The optimum determined regimen was $10 \mathrm{mg}$ ruxolitinib twice daily (after 1 cycle at $25 \mathrm{mg}$ twice a day) and $20 \mathrm{mg} / \mathrm{m}^{2}$ per day of decitabine for 5 days every 4 weeks [112]. Mascarenhas and colleagues [144] published the results of the multicenter phase 2 trial evaluating the aforementioned regimen during the production of this article.

Recently, Zhou and colleagues [90] reported a retrospective study of 42 patients, comprising 14 with MPNAP, 16 with MPN-BP, and 12 with HR MF, who were treated with decitabine monotherapy or in combination with ruxolitinib. Among the patients in AP, 7 received decitabine monotherapy and 6 were treated with ruxoli- tinib/decitabine combination. Over a median follow-up of 12.4 months (range, 2.1-48.8), the median OS of HR MF and MPN-AP patients was not reached; however, only 2 and 1 patients were alive at 60 months, respectively. After initiation of decitabine therapy, the probability of complete or partial (50\%) reduction in peripheral blasts was $54.6 \%$ in the entire cohort [90]. The investigators suggested that early initiation of decitabine or ruxolitinib/decitabine treatment in the accelerated phase conferred benefit to the patients and that the combination of ruxolitinib with decitabine was superior to decitabine monotherapy (the integrated cohort of HR MF, MPNAP, and MPN-BP patients had a median OS of 21.0 months with the combination vs. 12.9 months with decitabine only) [90].

Another study of 180 patients with MPN-AP/BP showed no difference in the outcomes with intensive chemotherapy compared to non-intensive therapy (hypomethylating agents, low-dose cytarabine, or treatment in a clinical study); the median OS of the entire group was 5.8 months. Intensive chemotherapy treatment was advantageous only in patients with $<4$ mutations and wildtype TP53 (median OS of 8.1 months for the latter group) [88].

\section{Treatments with Targeted Inhibitors}

In preclinical studies on MPN-BP cell lines, significant synergistic activity was noted between ruxolitinib in combination with bromodomain and extraterminal (BET) protein inhibitors, targeting epigenetic proteins [113]. The former preclinical studies provide grounds to conduct clinical studies assessing BET inhibitors/ruxolitinib in patients with MPN-AP/BP. In the ongoing global phase 2 MANIFEST trial (NCT02158858), patients with advanced MF-CP who had either suboptimal response to ruxolitinib treatment or were JAK-inhibitor naïve [114] showed notable clinical responses (spleen volume reduction and improvement in anemia, BM fibrosis, total symptom score, and transfusion dependence) after therapy with CPI-0610 (a selective BET inhibitor) alone or in combination with ruxolitinib [115].

Cotreatment with ruxolitinib and BET proteolysistargeting chimeras (BET-PROTACs, such as ARV-825) has also exhibited strong synergism against MPN-BP cells, and ARV-825 induced apoptosis in ruxolitinibresistant MPN-BP cells in vitro $[116,117]$. Accordingly, in another recent preclinical study, multi-targeted inhibition of the $\beta$-catenin-TCF7L2-JMJD6-c-Myc axis through co-treatment with the BET-PROTAC ARV-771 and the inhibitor BC2059 overcame resistance of patient-derived 
MPN-BP blasts to BET inhibitors and improved survival of mice engrafted with BET inhibitor-resistant MPN-BP cells [118]. Inhibitors of the heat shock protein 90 (Hsp90) degrade JAK2, and concomitant BET and Hsp90 inhibition had synergistic lethal activity against MPN-BP cells that were resistant to ruxolitinib $[113,119]$.

Notwithstanding limited advancements, the overall clinical experience of treating patients with MPN-AP/ $\mathrm{BP}$ clearly shows that a major unmet need still remains. As new targeted therapies are transforming the field of AML [18], molecularly targeted monotherapies or combinations with other agents engender promise in MPN-AP/BP [120]. Subgroups of patients harboring targetable mutations that are more frequent in MPNAP/BP than the chronic phase [121] (e.g., IDH1/2 occur at $\sim 20 \%$ frequency in MPN-BP vs. $\sim 4 \%$ in PMF [81]) may benefit from treatments with the corresponding inhibitors. For example, IDH1- and IDH2-mutated MPN-AP/BP can be treated with the oral IDH1 and IDH2 inhibitors ivosidenib and enasidenib, respectively, and their combinations with other drugs. Preclinical studies demonstrated synergism between enasidenib and ruxolitinib in double-mutant IDH2/JAK2 $2^{\mathrm{V} 617 \mathrm{~F}}$ MPN and MPN-BP patient-derived cells [122]. Notably, Patel et al. [123] and Chifotides et al. [124] recently conducted 2 retrospective studies in small cohorts of patients with $I D H 2$-mutated MPN-AP/BP and IDH1/2mutated MPN-BP, respectively. In the aforementioned studies, the patients were treated with enasidenib monotherapy (and azacitidine in 1 case) [123] and IDH1/2-inhibitor monotherapies or IDH1/2-inhibitorbased combinations with other drugs (hypomethylating agents, ruxolitinib, venetoclax, or intensive chemotherapy) [124], respectively; the patients demonstrated durable clinical responses with acceptable tolerability and survivals that compared favorably with historical reports. A phase 2 clinical trial evaluating the combination of enasidenib and ruxolitinib in patients with IDH2-mutant MPN-AP/BP and MF-CP (4-9\% circulating blasts) has been planned for the near future (NCT04281498; Table 3). Moreover, in another ongoing phase 1 clinical trial (NCT02074839), 6/11 patients with IDH1-mutated MPN-BP and co-occurring $J A K 2^{\mathrm{V} 617 \mathrm{~F}}$ at baseline were treated with ivosidenib monotherapy in the relapsed or refractory setting and achieved CR [125].

Venetoclax monotherapy has exhibited limited efficacy in myeloid malignancies, but combination strategies with other therapeutics are very promising in AML and are becoming the standard of care in patients aged $>75$ years
[126-128]. However, recent publications in a small number of patients indicate that venetoclax may not be an effective treatment in MPN-AP/BP patients (because $\mathrm{Bcl}-\mathrm{xl}$ is elevated in MPN-BP cells [129] and sensitivity to venetoclax correlates negatively with Bcl-xl levels [130]) except for patients harboring IDH1/2 mutations due to the production of R-2-hydroxyglutarate. Tremblay et al. [131] and Gangat et al. [132] conducted retrospective studies on small cohorts of MPN-BP patients treated with the combination of venetoclax and hypomethylating agents (decitabine or azacitidine): the median OSs were not extended compared to the historically poor survivals reported for MPN-BP. Notwithstanding the short OSs in both studies, a few patients achieved $\mathrm{CR}$ and $\mathrm{CR}_{\mathrm{i}}$; and underwent allo-HSCT. Notably, in a few recent preclinical and clinical studies, the investigators reported an increased sensitivity of $I D H 1 / 2$-mutated human AML cells and prolonged survival in IDH1/2-mutated AML patients with venetoclax [133-136]. In the report by Gangat and colleagues [132], the responses of 2 patients with IDH2-mutated BP-MPN revealed an analogous sensitivity to venetoclax-based combination treatment. In another recent report, a patient with $I D H 2$-mutated MPN-BP responded to venetoclax monotherapy [137]. A phase $1 / 2$ trial assessing ivosidenib/venetoclax with or without azacitidine in IDH1mutated patients with advanced malignancies, including MPN-AP/BP, is underway (NCT03471260; Table 3) [138]. Analysis of interim data from this study evaluating IDH1mutated patients who were treated with ivosidenib/venetoclax showed efficacy of the combination and promising response rates [139]. Considering that $\mathrm{MPN}-\mathrm{AP} / \mathrm{BP}$ patients have been largely excluded from clinical trials heretofore, this population will have the option to enroll in rationally designed clinical studies evaluating novel promising regimens, in this era.

A phase $1 / 2$ clinical study of KRT-232, an HDM2 inhibitor, in combination with either decitabine or lowdose cytarabine is underway for patients with AML, including MPN-BP (NCT04113616; Table 3). In this study, patients with TP53 mutations are excluded due to lack of activity of HDM2 inhibitors in mutated TP53. Approximately, $20 \%$ of the patients with MPN-AP/BP harbor TP53 [79]. Mutant TP53 AML [140] and TP53 MPN-AP/ BP $[88,141]$ have a poor prognosis and do not respond well to chemotherapy treatment. Novel agents are being developed for patients with mutated TP53. Notably, preliminary results with anti-programmed death ligand 1 (anti PD-L1) drugs have not shown clinically relevant results in patients with MPN-AP/BP [142]. 


\section{Conclusions}

In summary, MPN-AP is an aggressive disease that is considered a continuous transitional phase between MPN$\mathrm{CP}$ and MPN-BP and portends poor prognosis. Clinical practice and the limited number of studies that have been conducted heretofore demonstrated that advanced clinical features, such as rising blast counts ( $\geq 3-5 \%)$, acquisition of HMR mutations (ASXL1, IDH1/2, SRSF2, EZH2, $U 2 A F 1^{\mathrm{Q} 157}$, and TP53) and complex karyotype or high-risk cytogenetics (e.g., 17p deletion and gain of 1q), type 1 $C A L R$-unmutated status, severe anemia, and high-grade bone marrow fibrosis likely herald impending leukemic transformation. Regular clinical follow up and evaluation of factors indicating disease progression in high-risk patients are recommended, aiming to implement early therapeutic interventions and direct the patients to allo-HSCT [143]. In this respect, the prognostic models that were developed to assess the risk score of MPN patients can also predict the risk of transformation and have evolved significantly in the last $10+$ years. Hindrance of MPN progression to the $\mathrm{AP} / \mathrm{BP}$ and timely referral of eligible patients for alloHSCT are desirable goals whenever possible. Treatment with hypomethylating agents in combination with ruxolitinib provides an option for MPN-AP patients [111, 112, 144], instead of intensive chemotherapy, followed by an allo-HSCT. As more targeted therapies emerge for de novo AML, significant advancements are made in the molecular landscape of MPN-AP/BP; and patients with MPN-AP and actionable mutations will have the opportunity to be treated with new modalities and personalized schemes, for example, IDH1/2 inhibitors alone or in combination with other drugs. In this respect, wide implementation of next-generation sequencing is important. Additional novel inhibitors that are in clinical development, for example, BET inhibitors, provide promising venues that merit further assessment.

\section{Acknowledgement}

This work was supported, in part, by the MD Anderson Cancer Center Support Grant P30 CA016672 from the National Cancer Institute (National Institutes of Health).

\section{Conflict of Interest Statement}

P.B. has received research support from Incyte Corporation, Celgene (BMS), CTI Biopharma, Kartos Therapeutics, Blueprint Medicines, Constellation Pharmaceuticals, NS Pharma, Promedior, Astellas, and Pfizer. P.B. has received honoraria from Incyte Corporation, Celgene, CTI Biopharma, Kartos Therapeutics, and Blueprint Medicines. S.V. has received research support from Incyte Corporation, Roche, Celgene (BMS), Gilead, Promedior, CTI Biopharma Corporation, Genetech, Blueprint Medicines Corporation, NS Pharma, Novartis, Sierra Oncology, Pharma Essentia, Astra Zeneca, Italfarmaco, Kartos Therapeutics, Prelude Therapeutics, Protagonist Therapeutics, AbbVie, Constellation Pharmaceuticals, and Telios Pharmaceuticals. S.V. has received consultancy fees from Constellation Pharmaceuticals, Sierra Oncology, Incyte Corporation, Novartis, and Celgene. The remaining authors have no conflicts of interest to disclose.

\section{Author Contributions}

H.T.C. and O.A.S. reviewed the literature and wrote the review article. H.T.C. and O.A.S. contributed equally and share lead authorship. P.B. and L.M. reviewed the manuscript and made critical suggestions and modifications. S.V. conceived and guided the study; wrote and critically reviewed the article for important intellectual content. All authors approved the final version for submission.

\section{References}

1 Bose P, Masarova L, Amin HM, Verstovsek S. Philadelphia chromosome-negative myeloproliferative neoplasms (Chapter 6). In: Kantarjian HM, Wolff RA, Rieber AG, editors. The MD Anderson Manual of Medical Oncology. 4th ed. China: McGraw-Hill Education; 2021.

2 Marcellino BK, Verstovsek S, Mascarenhas J. The myelodepletive phenotype in myelofibrosis: Clinical relevance and therapeutic implications. Clin Lymphoma Myeloma Leuk. 2020;20(7):415-21.

3 Tefferi A, Cervantes F, Mesa R, Passamonti F, Verstovsek S, Vannucchi AM, et al. Revised response criteria for myelofibrosis: International Working Group-Myeloproliferative
Neoplasms Research and Treatment (IWGMRT) and European LeukemiaNet (ELN) consensus report. Blood. 2013;122(8):13958.

4 Quintás-Cardama A, Verstovsek S. Molecular pathways: JAK/STAT pathway: Mutations, inhibitors, and resistance. Clin Cancer Res. 2013;19(8):1933-40.

5 Schieber M, Crispino JD, Stein B. Myelofibrosis in 2019: Moving beyond JAK2 inhibition. Blood Cancer J. 2019;9(9):74.

6 Szuber N, Mudireddy M, Nicolosi M, Penna D, Vallapureddy RR, Lasho TL, et al. 3023 Mayo Clinic patients with myeloproliferative neoplasms: risk-stratified comparison of survival and outcomes data among dis- ease subtypes. Mayo Clin Proc. 2019;94(4): 599-610.

7 Yogarajah M, Tefferi A. Leukemic transformation in myeloproliferative neoplasms: a literature review on risk, characteristics, and outcome. Mayo Clin Proc. 2017;92(7):1118-28.

8 Cerquozzi S, Tefferi A. Blast transformation and fibrotic progression in polycythemia vera and essential thrombocythemia: a literature review of incidence and risk factors. Blood Cancer J. 2015;5(11):e366.

9 Abdulkarim K, Girodon F, Johansson P, Maynadié M, Kutti J, Carli PM, et al. AML transformation in 56 patients with Ph-MPD in two well defined populations. Eur J Haematol. 2009;82(2):106-11. 
10 Tam CS, Kantarjian H, Cortes J, Lynn A, Pierce S, Zhou L, et al. Dynamic model for predicting death within 12 months in patients with primary or post-polycythemia vera/essential thrombocythemia myelofibrosis. J Clin Oncol. 2009;27(33):5587-93.

11 Mudireddy M, Gangat N, Hanson CA, Ketterling RP, Pardanani A, Tefferi A. Validation of the WHO-defined $20 \%$ circulating blasts threshold for diagnosis of leukemic transformation in primary myelofibrosis. Blood Cancer J. 2018;8(6):57.

12 Mesa RA, Verstovsek S, Cervantes F, Barosi G, Reilly JT, Dupriez B, et al. Primary myelofibrosis (PMF), post polycythemia vera myelofibrosis (post-PV MF), post essential thrombocythemia myelofibrosis (post-ET MF), blast phase PMF (PMF-BP): Consensus on terminology by the international working group for myelofibrosis research and treatment (IWG-MRT). Leuk Res. 2007;31(6): 737-40.

13 Arber DA, Orazi A, Hasserjian R, Thiele J, Borowitz MJ, Le Beau MM, et al. The 2016 revision to the World Health Organization classification of myeloid neoplasms and acute leukemia. Blood. 2016;127(20):2391-405.

14 Grinfeld J, Nangalia J, Baxter EJ, Wedge DC, Angelopoulos N, Cantrill R, et al. Classification and personalized prognosis in myeloproliferative neoplasms. N Engl J Med. 2018; 379(15):1416-30.

15 Masarova L, Verstovsek S. The evolving understanding of prognosis in post-essential thrombocythemia myelofibrosis and postpolycythemia vera myelofibrosis vs primary myelofibrosis. Clin Adv Hematol Oncol. 2019;17(5):299-307.

16 Hidalgo López JE, Carballo-Zarate A, Verstovsek S, Wang SA, Hu S, Li S, et al. Bone marrow findings in blast phase of polycythemia vera. Ann Hematol. 2018;97(3):425-34.

17 Dunbar AJ, Rampal RK, Levine R. Leukemia secondary to myeloproliferative neoplasms. Blood. 2020;136(1):61-70.

18 Short NJ, Konopleva M, Kadia TM, Borthakur G, Ravandi F, DiNardo CD, et al. Advances in the treatment of acute myeloid leukemia: new drugs and new challenges. Cancer Discov. 2020;10(4):506-25.

19 Palandri F, Breccia M, Tiribelli M, Bonifacio M, Benevolo G, Iurlo A, et al. Risk factors for progression to blast phase and outcome in 589 patients with myelofibrosis treated with ruxolitinib: Real-world data. Hematol Oncol. 2020;38(3):372-80.

20 Mascarenhas J, Heaney ML, Najfeld V, Hexner E, Abdel-Wahab O, Rampal R, et al. Proposed criteria for response assessment in patients treated in clinical trials for myeloproliferative neoplasms in blast phase (MPN$\mathrm{BP})$ : formal recommendations from the postmyeloproliferative neoplasm acute myeloid leukemia consortium. Leuk Res. 2012;36(12): $1500-4$.

21 Takagi S, Masuoka K, Uchida N, Kurokawa M, Nakamae H, Imada K, et al. Allogeneic he- matopoietic cell transplantation for leukemic transformation preceded by Philadelphia chromosome-negative myeloproliferative neoplasms: a nationwide survey by the Adult Acute Myeloid Leukemia Working Group of the Japan Society for hematopoietic cell transplantation. Biol Blood Marrow Transp. 2016; 22(12):2208-13.

22 Alchalby $\mathrm{H}$, Zabelina T, Stübig T, van Biezen $\mathrm{A}$, Bornhäuser M, Di Bartolomeo P, et al. Allogeneic stem cell transplantation for myelofibrosis with Leukemic transformation: a study from the myeloproliferative neoplasm subcommittee of the CMWP of the European Group for Blood and Marrow Transplantation. Biol Blood Marrow Transp. 2014;20(2): 279-81.

23 Odenike O. How I treat the blast phase of Philadelphia chromosome-negative myeloproliferative neoplasms. Blood. 2018;132(22): 2339-50.

24 Mollard L-M, Chauveau A, Boyer-Perrard F, Douet-Guilbert N, Houot R, Quintin-Roué I, et al. Outcome of $\mathrm{Ph}$ negative myeloproliferative neoplasms transforming to accelerated or leukemic phase. Leukemia \& Lymphoma. 2018;59(12):2812-20.

25 Marcellino B, Mascarenhas J. Management of advanced phase myeloproliferative neoplasms. Clin Adv Hematol Oncol. 2019;17(7): 405-11.

26 Kennedy JA, Atenafu EG, Messner HA, Craddock KJ, Brandwein JM, Lipton JH, et al. Treatment outcomes following leukemic transformation in Philadelphia-negative myeloproliferative neoplasms. Blood. 2013; 121(14):2725-33.

27 Mannelli L, Guglielmelli P, Vannucchi AM. Stem cell transplant for the treatment of myelofibrosis. Expert Rev Hematol. 2020;13(4): 363-74.

28 Lancman G, Brunner A, Hoffman R, Mascarenhas J, Hobbs G. Outcomes and predictors of survival in blast phase myeloproliferative neoplasms. Leuk Res. 2018;70:49-55.

29 Chihara D, Kantarjian HM, Newberry KJ, Ravandi F, Daver NG, Bose P, et al. Survival outcome of patients with acute myeloid leukemia transformed from myeloproliferative neoplasms. Blood. 2016;128(22):1940.

30 Masarova L, Bose P, Pemmaraju N, Daver NG, Zhou L, Pierce S, et al. Prognostic value of blasts in peripheral blood in myelofibrosis in the ruxolitinib era. Cancer. 2020;126(19): 4322-31.

31 Masarova L, Bose P, Pemmaraju N, Daver N, Zhou L, Pierce S, et al. Clinical significance of bone marrow blast percentage in patients with myelofibrosis and the effect of Ruxolitinib therapy. Clin Lymph Myeloma Leuk. 2021;S2152-2650(20)31045-4

32 Geyer JT, Margolskee E, Krichevsky SA, Cattaneo D, Boiocchi L, Ronchi P, et al. Disease progression in myeloproliferative neoplasms: comparing patients in accelerated phase with those in chronic phase with increased blasts $(<10 \%)$ or with other types of disease pro- gression. Haematologica. 2020;105: e221e224.

33 Masarova L, Bose P, Zahr AA, Cortes J, Kan$\operatorname{tarjian} \mathrm{H}$, Verstovsek S. Do we need to re-define accelerated phase of myelofibrosis? Correlation between blast percentage in myelofibrosis and outcomes. Clin Lymphoma Myeloma Leuk. 2017;17(Suppl 2):S352.

34 Huang J, Li CY, Mesa RA, Wu W, Hanson CA, Pardanani A, et al. Risk factors for leukemic transformation in patients with primary myelofibrosis. Cancer. 2008;112(12):272632.

35 Vallapureddy RR, Mudireddy M, Penna D, Lasho TL, Finke CM, Hanson CA, et al. Leukemic transformation among 1306 patients with primary myelofibrosis: risk factors and development of a predictive model. Blood Cancer J. 2019;9(2):12.

36 Dupriez B, Morel P, Demory JL, Lai JL, Simon M, Plantier I, et al. Prognostic factors in agnogenic myeloid metaplasia: a report on 195 cases with a new scoring system. Blood. 1996; 88(3):1013-8.

37 Passamonti F, Rumi E, Elena C, Arcaini L, Merli M, Pascutto C, et al. Incidence of leukaemia in patients with primary myelofibrosis and RBC-transfusion-dependence. $\mathrm{Br} \mathrm{J}$ Haematol. 2010;150(6):719-21.

38 Bose $\mathrm{P}$, Verstovsek S. The evolution and clinical relevance of prognostic classification systems in myelofibrosis. Cancer. 2016;122(5): 681-92.

39 Cervantes F, Dupriez B, Pereira A, Passamonti F, Reilly JT, Morra E, et al. New prognostic scoring system for primary myelofibrosis based on a study of the International Working Group for Myelofibrosis Research and Treatment. Blood. 2009;113(13):2895901.

40 Passamonti F, Cervantes F, Vannucchi AM, Morra E, Rumi E, Pereira A, et al. A dynamic prognostic model to predict survival in primary myelofibrosis: a study by the IWG-MRT (International Working Group for Myeloproliferative Neoplasms Research and Treatment). Blood. 2010;115(9):1703-8.

41 Passamonti F, Cervantes F, Vannucchi AM, Morra E, Rumi E, Cazzola M, et al. Dynamic International Prognostic Scoring System (DIPSS) predicts progression to acute myeloid leukemia in primary myelofibrosis. Blood. 2010;116(15):2857-8.

42 Gangat N, Caramazza D, Vaidya R, George G, Begna K, Schwager S, et al. DIPSS plus: a refined dynamic international prognostic scoring system for primary myelofibrosis that incorporates prognostic information from karyotype, platelet count, and transfusion status. J Clin Oncol. 2011;29(4):392-7.

43 Guglielmelli P, Lasho TL, Rotunno G, Mudireddy M, Mannarelli C, Nicolosi M, et al. MIPSS70: Mutation-Enhanced International Prognostic Score System for transplantation-age patients with primary myelofibrosis. J Clin Oncol. 2018;36(4): $310-8$. 
44 Passamonti F, Giorgino T, Mora B, Guglielmelli P, Rumi E, Maffioli M, et al. A clinical-molecular prognostic model to predict survival in patients with post polycythemia vera and post essential thrombocythemia myelofibrosis. Leukemia. 2017;31:2726371.

45 Hussein K, Huang J, Lasho T, Pardanani A, Mesa RA, Williamson CM, et al. Karyotype complements the International Prognostic Scoring System for primary myelofibrosis. Eur J Haematol. 2009;82(4):255-9.

46 Caramazza D, Begna KH, Gangat N, Vaidya R, Siragusa S, Van Dyke DL, et al. Refined cytogenetic-risk categorization for overall and leukemia-free survival in primary myelofibrosis: a single center study of 433 patients. Leukemia. 2011;25(1):82-8.

47 Hussein K, Pardanani AD, Van Dyke DL, Hanson CA, Tefferi A. International prognostic scoring system-independent cytogenetic risk categorization in primary myelofibrosis. Blood. 2010;115(3):496-9.

48 Tefferi A, Nicolosi M, Mudireddy M, Lasho TL, Gangat N, Begna KH, et al. Revised cytogenetic risk stratification in primary myelofibrosis: analysis based on 1002 informative patients. Leukemia. 2018;32(5):1189-99.

49 Vaidya R, Caramazza D, Begna KH, Gangat N, Van Dyke DL, Hanson CA, et al. Monosomal karyotype in primary myelofibrosis is detrimental to both overall and leukemia-free survival. Blood. 2011;117(21):5612-5.

50 Tefferi A, Guglielmelli P, Lasho TL, Gangat N, Ketterling RP, Pardanani A, et al. MIPSS70+ Version 2.0: Mutation and karyotype-enhanced international prognostic scoring system for primary myelofibrosis. J Clin Oncol. 2018;36(17):1769-70.

51 Tefferi A, Guglielmelli P, Nicolosi M, Mannelli F, Mudireddy M, Bartalucci N, et al. GIPSS: Genetically Inspired Prognostic Scoring System for primary myelofibrosis. Leukemia. 2018;32(7):1631-42.

52 Masarova L, Bose P, Pemmaraju N, Estrov ZE, Zhou L, Pierce SA, et al. Evaluation of cytogenetic stratifications in myelofibrosis. Blood. 2018;132 (Suppl 1):1763 (section \#634).

53 Marcellino BK, Hoffman R, Tripodi J, Lu M, Kosiorek H, Mascarenhas J, et al. Advanced forms of MPNs are accompanied by chromosomal abnormalities that lead to dysregulation of TP53. Blood Adv. 2018;2(24):3581-9.

54 Milosevic JD, Kralovics R. Genetic and epigenetic alterations of myeloproliferative disorders. Int J Hematol. 2013;97(2):183-97.

55 Quintás-Cardama A, Kantarjian H, Pierce S, Cortes J, Verstovsek S. Prognostic model to identify patients with myelofibrosis at the highest risk of transformation to acute myeloid leukemia. Clin Lymphoma Myeloma Leuk. 2013;13(3):315-e2.

56 Tang G, Hidalgo López JE, Wang SA, Hu S, Ma J, Pierce S, et al. Characteristics and clinical significance of cytogenetic abnormalities in polycythemia vera. Haematologica. 2017; 102(9):1511-8.
57 Guglielmelli P, Rotunno G, Pacilli A, Rumi E, Rosti V, Delaini F, et al. Prognostic impact of bone marrow fibrosis in primary myelofibrosis. A study of the AGIMM group on 490 patients. Am J Hematol. 2016;91(9):918-22.

58 Pozdnyakova O, Hasserjian RP, Verstovsek S, Orazi A. Impact of bone marrow pathology on the clinical management of Philadelphia chromosome-negative myeloproliferative neoplasms. Clin Lymphoma Myeloma Leuk. 2015;15(5):253-61.

59 Dobrowolski J, Pasca S, Teodorescu P, Selicean C, Rus I, Zdrenghea M, et al. Persistent basophilia may suggest an "accelerated phase" in the evolution of CALR-positive primary myelofibrosis toward acute myeloid leukemia. Front Oncol. 2019;9:872. https://doi. org/10.3389/fonc.2019.00872.

60 Elliott MA, Verstovsek S, Dingli D, Schwager SM, Mesa RA, Li CY, et al. Monocytosis is an adverse prognostic factor for survival in younger patients with primary myelofibrosis. Leuk Res. 2007;31(11):1503-9.

61 Boiocchi L, Espinal-Witter R, Geyer JT, Steinhilber J, Bonzheim I, Knowles DM, et al. Development of monocytosis in patients with primary myelofibrosis indicates an accelerated phase of the disease. Mod Pathol. 2013; 26(2):204-12

62 Tefferi A, Shah S, Mudireddy M, Lasho TL, Barraco D, Hanson CA, et al. Monocytosis is a powerful and independent predictor of inferior survival in primary myelofibrosis. $\mathrm{Br} \mathrm{J}$ Haematol. 2018;183(5):835-8.

63 Cerquozzi S, Tefferi A. Blast transformation and fibrotic progression in polycythemia vera and essential thrombocythemia: a literature review of incidence and risk factors. Blood Cancer J. 2015;5:e366.

64 Nielsen I, Hasselbalch HC. Acute leukemia and myelodysplasia in patients with a Philadelphia chromosome negative chronic myeloproliferative disorder treated with hydroxyurea alone or with hydroxyurea after busulphan. Am J Hematol. 2003;74(1):26-31.

65 Björkholm M, Derolf AR, Hultcrantz M, Kristinsson SY, Ekstrand C, Goldin LR, et al. Treatment-related risk factors for transformation to acute myeloid leukemia and myelodysplastic syndromes in myeloproliferative neoplasms. J Clin Oncol. 2011;29(17):2410-5.

66 Barbui T, Carobbio A, Finazzi G, Guglielmelli P, Salmoiraghi S, Rosti V, et al. Elevated Creactive protein is associated with shortened leukemia-free survival in patients with myelofibrosis. Leukemia. 2013;27(10):2084-6.

67 Tefferi A, Vaidya R, Caramazza D, Finke C, Lasho T, Pardanani A. Circulating Interleukin (IL)-8, IL-2R, IL-12, and IL-15 levels are independently prognostic in primary myelofibrosis: a comprehensive cytokine profiling study. J Clin Oncol. 2011;29(10):1356-63.

68 Bose P, Verstovsek S. Mutational profiling in myelofibrosis: Implications for management. Int J Hematol. 2020;111(2):192-9.

69 Tefferi A, Lasho TL, Finke CM, Elala Y, Hanson CA, Ketterling RP, et al. Targeted deep sequencing in primary myelofibrosis. Blood Adv. 2016;1(2):105-11.

70 Rumi E, Pietra D, Pascutto C, Guglielmelli P, Martínez-Trillos A, Casetti I, et al. Clinical effect of driver mutations of JAK2, CALR, or MPL in primary myelofibrosis. Blood. 2014; 124(7):1062-9.

71 Tefferi A, Guglielmelli P, Larson DR, Finke C, Wassie EA, Pieri L, et al. Long-term survival and blast transformation in molecularly annotated essential thrombocythemia, polycythemia vera, and myelofibrosis. Blood. 2014; 124(16):2507-615.

72 Tefferi A, Guglielmelli P, Lasho TL, Rotunno G, Finke C, Mannarelli C, et al. CALR and ASXL1 mutations-based molecular prognostication in primary myelofibrosis: an international study of 570 patients. Leukemia. 2014;28(7):1494-500.

73 Vannucchi AM, Lasho TL, Guglielmelli P, Biamonte F, Pardanani A, Pereira A, et al. Mutations and prognosis in primary myelofibrosis. Leukemia. 2013;27(9):1861-9.

74 Tefferi A, Finke CM, Lasho TL, Hanson CA, Ketterling RP, Gangat N, et al. U2AF1 mutation types in primary myelofibrosis: phenotypic and prognostic distinctions. Leukemia. 2018;32(10):2274-8.

75 Tefferi A, Guglielmelli P, Pardanani A, Vannucchi AM. Myelofibrosis treatment algorithm 2018. Blood Cancer J. 2018;8(8):72.

76 Santos FPS, Getta B, Masarova L, Famulare C, Schulman J, Datoguia TS, et al. Prognostic impact of RAS-pathway mutations in patients with myelofibrosis. Leukemia. 2020;34(3):799-810.

77 Harutyunyan A, Klampfl T, Cazzola M, Kralovics R. p53 lesions in leukemic transformation. N Engl J Med. 2011;364(5):488-90.

78 Rampal R, Ahn J, Abdel-Wahab O, Nahas M, Wang K, Lipson D, et al. Genomic and functional analysis of leukemic transformation of myeloproliferative neoplasms. Proc Natl Acad Sci U S A. 2014;111(50):E5401-10.

79 Lundberg P, Karow A, Nienhold R, Looser R, Hao-Shen H, Nissen I, et al. Clonal evolution and clinical correlates of somatic mutations in myeloproliferative neoplasms. Blood. 2014; 123(14):2220-8.

80 Lasho TL, Mudireddy M, Finke CM, Hanson CA, Ketterling RP, Szuber N, et al. Targeted next-generation sequencing in blast phase myeloproliferative neoplasms. Blood Adv. 2018;2(4):370-80.

81 Tefferi A, Lasho TL, Abdel-Wahab O, Guglielmelli P, Patel J, Caramazza D, et al. IDH1 and IDH2 mutation studies in 1473 patients with chronic-, fibrotic- or blast-phase essential thrombocythemia, polycythemia vera or myelofibrosis. Leukemia. 2010;24(7):1302-9.

82 Rampal R, Mascarenhas J. Pathogenesis and management of acute myeloid leukemia that has evolved from a myeloproliferative neoplasm. Curr Opin Hematol. 2014;21(2):65-71.

83 Abdel-Wahab O, Manshouri T, Patel J, Harris $\mathrm{K}$, Yao J, Hedvat C, et al. Genetic analysis of transforming events that convert chronic myeloproliferative neoplasms to leukemias. Cancer Res. 2010;70(2):447-52. 
84 Tallarico M, Odenike O. Secondary acute myeloid leukemias arising from Philadelphia chromosome negative myeloproliferative neoplasms: pathogenesis, risk factors, and therapeutic strategies. Curr Hematol Malig Rep. 2015;10(2):112-7.

85 Zhang SJ, Rampal R, Manshouri T, Patel J, Mensah N, Kayserian A, et al. Genetic analysis of patients with leukemic transformation of myeloproliferative neoplasms shows recurrent SRSF2 mutations that are associated with adverse outcome. Blood. 2012;119(19):4480-5.

86 Pardanani A, Lasho TL, Finke CM, Mai M, McClure RF, Tefferi A. IDH1 and IDH2 mutation analysis in chronic- and blast-phase myeloproliferative neoplasms. Leukemia. 2010;24(6):1146-51.

87 Tefferi A, Lasho TL, Guglielmelli P, Finke CM, Rotunno G, Elala Y, et al. Targeted deep sequencing in polycythemia vera and essential thrombocythemia. Blood. 2016;1(1):21-30.

88 McNamara CJ, Panzarella T, Kennedy JA, Arruda A, Claudio JO, Daher-Reyes G, et al. The mutational landscape of accelerated- and blastphase myeloproliferative neoplasms impacts patient outcomes. Blood Adv. 2018;2(20):2658-71.

89 Guo Y, Zhou Y, Yamatomo S, Yang H, Zhang $\mathrm{P}$, Chen S, et al. ASXL1 alteration cooperates with JAK2V617F to accelerate myelofibrosis. Leukemia. 2019;33(5):1287-91.

90 Zhou S, Tremblay D, Hoffman R, Kremyanskaya M, Najfeld V, Li L, et al. Clinical benefit derived from decitabine therapy for advanced phases of myeloproliferative neoplasms. Acta Haematol. 2021;144(1):48-57.

91 Benton CB, Boddu PC, DiNardo CD, Bose P, Wang F, Assi R, et al. Janus kinase 2 variants associated with the transformation of myeloproliferative neoplasms into acute myeloid leukemia. Cancer. 2019;125(11):1855-66.

92 Mascarenhas J. A concise update on risk factors, therapy, and outcome of leukemic transformation of myeloproliferative neoplasms. Clin Lymphoma Myeloma Leuk. 2016; 16(Suppl. 1):S124-9.

93 Mannelli F. Acute myeloid leukemia evolving from myeloproliferative neoplasms: many sides of a challenging disease. J Clin Med. 2021;10(3):436

94 Gagelmann N, Ditschkowski M, Bogdanov R, Bredin S, Robin M, Cassinat B, et al. Comprehensive clinical-molecular transplant scoring system for myelofibrosis undergoing stem cell transplantation. Blood. 2019;133(20):2233-42.

95 Mannelli L, Guglielmelli P, Vannucchi AM. Stem cell transplant for the treatment of myelofibrosis. Expert Rev Hematol. 2020;13(4): 363-74.

96 Gowin K, Ballen K, Ahn KW, Hu ZH, Ali H, Arcasoy MO, et al. Survival following allogeneic transplant in patients with myelofibrosis. Blood Adv. 2020;4(9):1965-73.

97 NCCN Cinical Practice Guidelines in Oncology (NCCN Guidelines). Myeloproliferative Neoplasms (version I.2020). Available from: https:// www.nccn.org/professionals/physician gls/default.aspx. Last accessed: October 3, 2020.
98 Döhner H, Estey E, Grimwade D, Amadori S, Appelbaum FR, Büchner T, et al. Diagnosis and management of AML in adults: 2017 ELN recommendations from an International Expert Panel. Blood. 2017;129(4): 424-47.

99 Mascarenhas J, Heaney ML, Najfeld V, Hexner E, Abdel-Wahab O, Rampal R, et al. Proposed criteria for response assessment in patients treated in clinical trials for myeloproliferative neoplasms in blast phase (MPN-BP): formal recommendations from the Post-Myeloproliferative Neoplasm Acute Myeloid Leukemia Consortium. Leuk Res. 2012;36(12):1500-4.

100 Devillier R, Raffoux E, Rey J, Lengline E, Ronchetti AM, Sebert M, et al. Combination therapy with ruxolitinib plus intensive treatment strategy is feasible in patients with blast-phase myeloproliferative neoplasms. Br J Haematol. 2016;172(4):628-30.

101 Tam CS, Nussenzveig RM, Popat U, BuesoRamos CE, Thomas DA, Cortes JA, et al. The natural history and treatment outcome of blast phase BCR-ABL- myeloproliferative neoplasms. Blood. 2008;112(5):162837.http://dx.doi.org/10.1182/blood-200802-138230.BCR-ABL

102 Dumas PY, Bertoli S, Bérard E, Médiavilla C, Yon E, Tavitian S, et al. Azacitidine or intensive chemotherapy for older patients with secondary or therapy-related acute myeloid leukemia. Oncotarget. 2017;8(45): 79126-36.

103 Thepot S, Itzykson R, Seegers V, Raffoux E, Quesnel B, Chait Y, et al. Treatment of progression of Philadelphia-negative myeloproliferative neoplasms to myelodysplastic syndrome or acute myeloid leukemia by azacitidine: a report on 54 cases on the behalf of the Groupe Francophone des Myelodysplasies (GFM). Blood. 2010;116(19):3735-42.

104 Andriani A, Montanaro M, Voso MT, Villivà $\mathrm{N}$, Ciccone $\mathrm{F}$, Andrizzi $\mathrm{C}$, et al. Azacytidine for the treatment of retrospective analysis from the Gruppo Laziale for the study of Ph-negative MPN. Leuk Res. 2015;39(8): $801-4$

105 Andriani A, Elli E, Trapè G, Villivà N, Fianchi L, Di Veroli A, et al. Treatment of Philadelphia-negative myeloproliferative neoplasms in accelerated/blastic phase with azacytidine. Clinical results and identification of prognostic factors. Hematol Oncol. 2019;37(3):291-5.

106 Drummond MW, Harrison CN, Vicente SM, Mead AJ, Yap C, Chen F, et al. A Phase Ib to assess the safety and tolerability of ruxolitinib in combination with azacitidine in patients with advanced phase myeloproliferative neoplasms (MPN), including myelodysplastic syndromes (MDS) or acute myeloid leukemia (AML) arising from MPN (The Bloodwise/TAP PHAZAR study on behalf of the UK MPN CGS). Blood. 2017; 130(Suppl 1):1649.
107 Masarova L, Verstovsek S, Hidalgo-Lopez JE, Pemmaraju N, Bose P, Estrov Z, et al. A phase 2 study of ruxolitinib in combination with azacitidine in patients with myelofibrosis. Blood. 2018;132(16):1664-74.

108 Badar T, Kantarjian HM, Ravandi F, Jabbour E, Borthakur G, Cortes JE, et al. Therapeutic benefit of decitabine, a hypomethylating agent, in patients with high-risk primary myelofibrosis and myeloproliferative neoplasm in accelerated or blastic/acute myeloid leukemia phase. Leuk Res. 2015; 39(9):950-6.

109 Eghtedar A, Verstovsek S, Estrov Z, Burger J, Cortes J, Bivins C, et al. Phase 2 study of the JAK kinase inhibitor ruxolitinib in patients with refractory leukemias, including postmyeloproliferative neoplasm acute myeloid leukemia. Blood. 2012;119(20):4614-8.

110 Bose P, Verstovsek S, Gasior Y, Jain N, Jabbour EJ, Estrov Z, et al. Phase I/II study of ruxolitinib (RUX) with decitabine (DAC) in patients with post-Myeloproliferative Neoplasm Acute Myeloid Leukemia (post-MPN AML) phase I results. Blood. 2016;128(22):4262

111 Bose P, Verstovsek S, Cortes JE, Tse S, Gasior Y, Jain N, et al. A phase 1/2 study of ruxolitinib and decitabine in patients with post-myeloproliferative neoplasm acute myeloid leukemia. Leukemia. 2020;34(9): 2489-92.

112 Rampal RK, Mascarenhas JO, Kosiorek HE, Price L, Berenzon D, Hexner E, et al. Safety and efficacy of combined ruxolitinib and decitabine in accelerated and blast-phase myeloproliferative neoplasms. Blood Adv. 2018;2(24):3572-80

113 Saenz DT, Fiskus W, Manshouri T, Rajapakshe K, Krieger S, Sun B, et al. BET protein bromodomain inhibitor-based combinations are highly active against post-myeloproliferative neoplasm secondary AML cells. Leukemia. 2017;31(3):678-87.

114 Mascarenhas J, Harrison C, Patriarca A, Devos T, Palandri F, Rampal R, et al. CPI-0610, a Bromodomain and Extraterminal Domain Protein (BET) inhibitor, in combination with ruxolitinib, in JAK-inhibitor treatment naïve myelofibrosis patients: Update from MANIFEST phase 2 study. HemaSphere. 2020;4(S1, abstract EP1084):499.

115 Verstovsek S, Mascarenhas J, Kremyanskaya M, Hoffman R, Rampal R, Gupta V, et al. CPI0610, Bromodomain and Extraterminal Domain Protein (BET) inhibitor, as "add-on" to ruxolitinib (RUX), in advanced myelofibrosis patients with suboptimal response: update of MANIFEST phase 2 study. HemaSphere. 2020;4(S1, abstract EP1083):499.

116 Saenz DT, Fiskus W, Qian Y, Manshouri T, Rajapakshe K, Raina K, et al. Novel BET protein proteolysis-targeting chimera exerts superior lethal activity than bromodomain inhibitor (BETi) against post-myeloproliferative neoplasm secondary (s)AML cells. Leukemia. 2017;31(9):1951-61. 
117 Verstovsek S, Fiskus W, Manshouri T, Bhalla KN. Targeting cistrome and dysregulated transcriptome of post-MPN sAML. Oncotarget. 2017;8(55):93301-2.

118 Saenz DW, Fiskus W, Mill CP, Perera D, Manshouri T, Lara BH, et al. Mechanistic basis and efficacy of targeting $\beta$-cateninTCF7L2-JMJD6-c-Myc axis to overcome resistance to BET inhibitors. Blood. 2020; 135(15): 1255-69.

119 Bhagwat N, Koppikar P, Keller M, Marubayashi S, Shank K, Rampal R, et al. Improved targeting of JAK2 leads to increased therapeutic efficacy in myeloproliferative neoplasms. Blood. 2014;123(13): 2075-83.

120 Scherber RM, Mesa RA. Management of challenging myelofibrosis after JAK inhibitor failure and/or progression. Blood Rev. 2020 May 30;42:100716.

121 Green A, Beer P. Somatic mutations of IDH1 and IDH2 in the leukemic transformation of myeloproliferative neoplasms. $\mathrm{N}$ Engl J Med. 2010;362(4):369-70.

122 McKenney AS, Allison NL, Hanasoge Somasundra AV, Spitzer B, Intlekofer AM, et al. JAK2/IDH-mutant-driven myeloproliferative neoplasm is sensitive to combined targeted inhibition. J Clinical Invest. 2018; 128(2):789-804. http://10.1172/JCI124920.

123 Patel AA, Cahill K, Charnot-Katsikas A, Liu $\mathrm{H}$, Gurbuxani S, Thirman M, et al. Clinical outcomes of IDH2-mutated advancedphase $\mathrm{Ph}$-negative myeloproliferative neoplasms treated with enasidenib. Br J Haematol. 2020;190(1):e48-51.

124 Chifotides HT, Masarova L, Alfayez M, Daver N, Alvarado Y, Jabbour E, et al. Outcome of patients with IDH1/2-mutated post-myeloproliferative neoplasm AML in the era of IDH inhibitors. Blood Adv. 2020; 4(21):5336-42.

125 Choe S, Wang H, DiNardo CD, Stein EM, de Botton S, Roboz GJ, et al. Molecular mechanisms mediating relapse following ivosidenib monotherapy in IDH1-mutant relapsed or refractory AML. Blood Adv. 2020;4(9):1894-905.

126 DiNardo CD, Jonas BA, Pullarkat V, Thirman MJ, Garcia JS, Wei AH, et al.
Azacitidine and venetoclax in previously untreated acute myeloid leukemia. $\mathrm{N}$ Engl J Med. 2020;383(7):617-29.

127 Lachowiez C, DiNardo CD, Konopleva M. Venetoclax in acute myeloid leukemia current and future directions. Leukemia \& Lymphoma. 2020;61(6):1313-22.

128 DiNardo CD, Maiti A, Rausch CR, Pemmaraju N, Naqvi K, Daver NG, et al. 10day decitabine with venetoclax for newly diagnosed intensive chemotherapy ineligible, and relapsed or refractory acute myeloid leukaemia: a single-centre, phase 2 trial. Lancet Haematol. 2020;7(10):e72436.

129 Petiti J, Lo lacono M, Rosso V, Andreani G, Jovanovski A, Podesta $\mathrm{M}$, et al. Bcl-xl represents a therapeutic target in Philadelphia negative myeloproliferative neoplasms. J Cell Mol Med. 2020;24:10978-86.

130 Pan R, Hogdal L J, Benito J M, Bucci D, Lina $\mathrm{H}$, Borthakur G, et al. Selective BCL-2 inhibition by ABT-199 causes on-target cell death in acute myeloid leukemia. Cancer Disc. 2014;4(3):362-75.

131 Tremblay D, Feld J, Dougherty M, Czaplinska T, Sanchez G, Kremyanskaya M, et al. Venetoclax and hypomethylating agent combination therapy in acute myeloid leukemia secondary to a myeloproliferative neoplasm. Leuk Res. 2020;98:106456.

132 Gangat N, Morsia E, Foran JM, Palmer JM, Elliott MA, Tefferi A. Venetoclax plus hypomethylating agent in blast-phase myeloproliferative neoplasm: Preliminary experience with 12 patients. Br J Haematol. 2020 Dec;191(5):e120-4.

133 Pollyea DA, Amaya M, Strati P, Konopleva MY. Venetoclax for AML: changing the treatment paradigm. Blood Adv. 2019; 3(24):4326-35.

134 Konopleva M, Pollyea DA, Potluri J, Chyla B, Hogdal L, Busman T, et al. Efficacy and biological correlates of response in a phase II study of venetoclax monotherapy in patients with acute myelogenous leukemia. Cancer Discov. 2016;6(10):1106-17.

135 Chyla B, Daver N, Doyle K, McKeegan E, Huang X, Ruvolo V, et al. Genetic biomarkers of sensitivity and resistance to veneto- clax monotherapy in patients with relapsed acute myeloid leukemia. Am J Hematol. 2018;93(8):E202-5.

136 DiNardo CD, Tiong IS, Quaglieri A, MacRaild S, Loghavi S, Brown FC, et al. Molecular patterns of response and treatment failure after frontline venetoclax combinations in older patients with AML. Blood. 2020; 135(11):791-803.

137 Huemer F, Melchardt T, Jansko B, Wahida A, Jilg S, Jost PJ, et al. Durable remissions with venetoclax monotherapy in secondary AML refractory to hypomethylating agents and high expression of BCL-2 and/or BIM. Eur J Haematol. 2019;102(5):437-41.

138 Lachowiez CA, Borthakur G, Loghavi S, et al. Phase Ib/II study of the IDH1-mutant inhibitor ivosidenib with the BCL2 inhibitor venetoclax +/- azacitidine in IDH1-mutated hematologic malignancies. J Clin Oncol. 2020;38(Suppl 15):7500.

139 DiNardo C, Takahashi K, Kadia T, Loghavi S, Naqvi K, Bose P, et al. A phase 1b/2 clinical study of targeted IDH1 inhibition with ivosidenib, in combination with the Bcl-2 inhibitor venetoclax, for patients with IDH1-mutated (MIDH1) myeloid malignancies. HemaSphere. 2019;3(S1):97

140 Rücker FG, Schlenk RF, Bullinger L, Kayser S, Teleanu V, Kett H, et al. TP53 alterations in acute myeloid leukemia with complex karyotype correlate with specific copy number alterations, monosomal karyotype, and dismal outcome. Blood. 2012;119(9):2114-21.

141 Venton G, Courtier F, Charbonnier A, D'incan E, Saillard C, Mohty B, et al. Impact of gene mutations on treatment response and prognosis of acute myeloid leukemia secondary to myeloproliferative neoplasms. Am J Hematol. 2018;93(3):330-8.

142 Verstovsek S. Personal communication.

143 Jain T, Rampal RK. Accelerated and blast phase myeloproliferative neoplasms. Hematol Clin North Am. 2021;35(2):325-35.

144 Mascarenhas J, Rampal RK, Kosiorek HE, et al. Phase 2 study of ruxolitinib and decitabine in patients with myeloproliferative neoplasm in accelerated and blast phase. Blood Adv. 2020;4(20):5246-56. 